Frontiers: The Interdisciplinary Journal of Study Abroad

(C) 2021 Susan B. Goldstein \& Henry N. Lopez

The work is licensed under the Creative Commons Attribution-NonCommercial-NoDerivatives

4.0 International License.

Volume 33, Issue 2, pp. 1-16

DOI 10.36366/frontiers.v33i2.534

FORUM

ON EDUCATION

ABROAD

\title{
An Intersectional Investigation of Study Abroad Intent among Latino/a and White First- generation College Students
}

\author{
Susan B. Goldstein ${ }^{1}$, Henry N. Lopez²
}

\begin{abstract}
Despite a marked increase in study abroad participation in recent decades, first-generation students and Students of Color remain vastly underrepresented. The current study sought to expand the extant literature on first-generation and Latino/a students' study abroad participation by applying an intersectional approach to identifying predictors of study abroad intent. A total of 478 undergraduates (Latino/a and White; first-generation and continuing-generation) completed a questionnaire based on previously identified predictors of study abroad intent. Separate binary logistic regression analyses for each of the four (ethnicity $x$ generational status) subgroups indicated that personality and intercultural variables predicted intent to study abroad solely for the White continuing-generation students. Exposure to study abroad was a primary predictor of intent across subgroups, yet significant between-group differences emerged regarding the source and extent of this exposure. Implications for study abroad advising and inclusive participation are discussed.
\end{abstract}

\section{Keywords:}

study abroad, first-generation college students, Latino/a, intersectionality

\section{Introduction}

Over the past decade, scholars and practitioners have increasingly sounded the alarm about inequities in U.S. students' study abroad participation (e.g., Bruz \& Fry, 2010; Salisbury et al., 2011). Although the diversity of study abroad participants has grown

1 UNIVERSITY OF REDLANDS, REDLANDS, CA, USA

2 San Diego State University, San Diego, CA, USA

Corresponding author: Susan Goldstein, susan goldstein@redlands.edu 
somewhat in recent years, there remain multiple underrepresented groups, including Students of Color and first-generation (FG) students. The term first-generation student is defined by most educational researchers as a student without a parent or guardian who has completed a bachelor's degree (Toutkoushian et al., 2018). As compared with continuing-generation (CG) students, FG students are more likely to be Students of Color and to come from low-income households (Tolan \& McCullers, 2018).

Although FG students make up approximately one-third of those enrolled in U.S. post-secondary institutions (Cataldi et al., 2018), only 9\% of FG college seniors reported participating in study abroad as compared with $20 \%$ of their CG peers (National Survey of Student Engagement, 2020). Of the 347,099 U.S. students who participated in study abroad during the 2018-2019 academic year, 31\% identified as Students of Color, whereas 69\% identified as White (Institute of International Education, 2020). Like FG students, Students of Color study abroad at numbers disproportionate to their college enrollment. For example, Latino/ $\mathrm{a}^{1}$ students participated in study abroad at a rate approximately half of what would be expected based on enrollment numbers (McClure et al., 2010).

Access to study abroad is a matter of educational equity, as it is one of several high impact practices (HIPs) associated with greater student retention and engagement (Kuh, 2008). These HIPs may be particularly impactful for students from underrepresented groups such as FG students (Kuh, 2008), who are at greater risk of not completing their college degree (U.S. Census, 2010). However, due in part to intuitional barriers, FG students are less likely than their CG counterparts to have been informed about HIPs and the benefits of these practices to their undergraduate career (Demetriou et al., 2017).

Calls for more inclusive participation in study abroad often focus on the benefits specific to this HIP, which prepare students for a rapidly changing and globally interconnected economy (Tolan \& McCullers, 2018). These include greater emotional resilience, (Earnest et al., 2016), intercultural competence, global understanding, and world mindedness (Behrnd \& Porzelt, 2010; Douglas \& Joan-Rikkers, 2001; Kitsantas, 2004), increased foreign language interest and competence (Opper et al., 1990), and greater environmental citizenship (Tarrant et al., 2013; Wynveen, et al., 2012). For FG students in particular, study abroad was also associated with degree completion as well as self-assessed independence, self-confidence, and willingness to engage with unfamiliar individuals and activities (Demetriou et al., 2017). Students who are unable to study abroad are not only excluded from these benefits but also from certain academic programs that include study abroad as a requirement. For example, Wilkie (2017) described a university with at least 32 majors and minors that require an international experience. Given these advantages, equal access to study abroad has been described as a social justice issue (Martinez et al., 2010). Sweeney (2013, p.1) stated that it is thus critical that researchers better understand the "pathways to study abroad" for students from underrepresented groups.

Previous research has identified several predictors of study abroad intent and participation, including female gender, concern about completing one's major, positive expectations of study abroad, interest in language learning, intergroup attitudes, such as prejudice and ethnocentrism, and personality traits, such as openness to experience and adventurousness (Goldstein\& Kim, 2006; Li et al., 2013; Luo \& Jamieson-Drake, 2015;

\footnotetext{
${ }^{1}$ We appreciate the inclusive intent behind the terms "Latina/o" and "Latinx," but have opted to use the term "Latino/a" as it may better reflect the values, traditions, and preferences of members of the diverse community it describes (de Onis, 2017; Salinas, 2020).
} 
Schroth \& McCormack, 2000; Stroud, 2010). Yet these findings may be less relevant to FG students, given their unique set of life circumstances and potential barriers.

\section{An Intersectional Approach}

Although there exists limited research on the study abroad participation of FG students and Students of Color, to our knowledge no quantitative study has investigated how these identities may interact. As compared to conventional methodology, this intersectional approach more accurately characterizes the lived experiences of participant groups and thus allows post-secondary institutions to develop targeted interventions to reach equity outcomes (Christoffersen, 2017; Museus \& Griffin, 2011). Orbe (2004), for example, identified policy implications of his finding that the salience of FG status tends to be greater for Students of Color than for their White counterparts. Such studies reinforce the need to consider the multidimensional nature of students' identities. The current investigation concerns the intersectional identities of Latino/a and White, FG and CG students. ${ }^{2}$ We have focused on the experiences of Latino/a students in particular, as they are the fastest growing student group on U.S. college campuses (U.S. Department of Education, 2019) and are underrepresented in the study abroad research literature (Chang, 2017).

\section{Study Abroad Considerations for FG and Latino/a Students}

Researchers have identified a fairly consistent set of barriers to study abroad intent and participation among FG students and Students of Color ${ }^{3}$ (Blake et al., 2019; Engle, 2017; Willis, 2015). Such obstacles stem from both individual- and institutional-level conditions and include lack of exposure to study abroad, financial constraints and work obligations, concern about degree completion, family obligations and influence, anticipated discrimination, lack of personally relevant programs, and exclusionary marketing practices.

FG students may receive less exposure to the notion of study abroad than do CG students, both through formal and informal channels. Academic advisors who work with FG students may view study abroad as less feasible for these students or their advising sessions may be dominated by other concerns. A Council for Opportunity in Education survey of staff members who work with FG students found many to be themselves unfamiliar with study abroad or to be unconvinced of its value (Martinez et al., 2010). Since FG and Latino/a students tend to spend less time on campus (due to commuting, family obligations, and longer work hours), they may be less likely than their White CG counterparts to hear about the study abroad experiences of their peers - a key informal mechanism shaping study abroad intent (McClure et al., 2010; Whatley, 2018).

Cost is a central barrier to study abroad (Whatley, 2017). Although tuition and program fees may be covered by financial aid or scholarships, there are considerable upfront costs, such as airfare, passport and visa charges, and medical exams or vaccines, that typically fall to the student (Wilkie, 2017). FG students also face the opportunity costs

\footnotetext{
${ }^{2}$ In the current study we make comparisons between Latino/a and White students to expand the extant study abroad literature, which has focused primarily on a White student population. In doing so, we aim to challenge, and not reinforce, positions of White normativity.

${ }^{3}$ We indicate intersectionality by citing overlapping groups (e.g., Latino/a and FG), which include all members of each category as well as the intersecting identities (in this instance, Latino/a CG and FG students and all other FG students, regardless of ethnicity).
} 
of not engaging in paid work while abroad, since they are more likely to have off-campus jobs during the school year and to work longer hours than their CG peers to assist with family expenses or to finance their education (Martin, 2015; McClure et al., 2010; Pascarella et al., 2004; Tolan \& McCullers, 2018). Working long hours during the school year may indirectly disadvantage FG students when applying to study abroad programs or scholarships with a minimum GPA requirement, since work obligations may make it difficult to find adequate time to devote to studies. In addition to costs associated with study abroad itself, students with limited financial resources, often FG college students and Student of Color, may be concerned that a study abroad experience will delay their degree completion and that they will thus incur increased tuition payments (McClure et al., 2010).

Family opinions and expectations may be a deterrent to study abroad for Latino/a and FG students, particularly since they are more likely than their White CG peers to live at home and shoulder family responsibilities (Azmitia et al., 2018). For Latino/a students, this sense of responsibility may be strengthened by familismo, which Tello and Lonn (2017) describe as a core aspect of Latino/a culture, emphasizing family cohesion and prioritizing family over the individual. The expectation that one may need to assist in family matters could make it difficult for students to make a commitment to study abroad (McClure et al., 2010), which is often required as much as a year in advance of the program start date. As compared with the families of CG students, those of FG students tend to be less familiar with study abroad and to view it less favorably (Brux \& Fry, 2010). For the many FG students whose parents struggled to immigrate, it may be difficult to make a convincing argument for the need to leave the country, either for international or academic experiences (Wilkie, 2017), particularly when neither the student nor the parent has experience with study abroad.

Finally, Latino/a and FG students may be deterred from study abroad due to providers' or institutions' exclusionary marketing which features portrayals dominated by affluent White individuals seeking adventure by interacting with a culture that differs from their own (Gathogo \& Horton, 2018). Although previous research has linked adventurousness with interest in study abroad and more immersive programs (Goldstein, 2015; Li et al., 2013; Schroth \& McCormack, 2000), there is reason to believe that adventurousness may be a weaker predictor of Latino/a and FG students' intent to study abroad, particularly if doing so is framed as largely recreational (Gathogo \& Horton, 2018). Since most post-secondary institutions are geared toward students raised with dominant culture, middle class values (Stephens et al., 2012), Latino/a and FG students' initial encounters with college may be similar to "entering an 'alien culture" (Orbe, 2004, p. 133). Thus, for these students, promotional materials that emphasize interacting across cultures may be less compelling if doing so is already an everyday experience.

Nonetheless, these same life experiences that result in a sense of outsider status relative to the dominant culture may require FG, and Latino/a students in particular, to develop skills that are advantageous in a study abroad context. Orbe (2004, p. 133) suggested that "negotiating multiple layers of identity" is central to FG students' ability to move between the requirements of home and school environments. Such cultural navigational skills are valuable in study abroad experiences which require students to interact with individuals who differ from themselves on multiple dimensions (e.g., language and communication practices; social norms). Volpone et al. (2018), for example, found an association between the number of minority statuses experienced by international students in their home country and degree of acculturation to the host culture. 
Lu et al. (2015, p. 446) reported that Black students studying in China capitalized on the ability to code switch to facilitate intercultural communication and "were less concerned about 'looking different from everyone there' compared to their White counterparts because they were already used to being a racial minority...”. Students studying in heritage destinations may also draw on forms of community capital to facilitate a successful study abroad experience. For example, Wick et al. (2019) found that Latino/a students studying in Costa Rica were able to take advantage of their pre-existing strengths through familial, aspirational, linguistic, and resistant capital to frame and enhance their abroad experience.

Thus, based on the aforementioned study abroad considerations for FG and Latino/a students, we predicted:

1. Significantly greater scores on intent to study abroad, perceived likelihood of studying abroad, and ease of imagining oneself abroad for CG than for FG participants and for White than Latino/a students, respectively.

2. A different set of predictors for study abroad intent for FG as compared to CG students.

a. For FG students we expected that study abroad intent would be predicted by: Gender, ethnicity, income, heritage language, exposure to study abroad, concern about completing one's major, and family attitudes.

b. For CG students, we predicted that study abroad intent would additionally be predicted by adventurousness and the intercultural attitudes of intercultural communication apprehension and ethnocentrism.

3. To investigate intersectionality, we focused on the interaction of ethnicity with generational status. We expected that adventurousness and the intercultural variables would more strongly predict study abroad intent for White CG students as compared to FG and Latino/a students.

\section{Method}

This study received Institutional Review Board (IRB) approval and all procedures (e.g., recruitment, informed consent, confidentiality, debriefing, and data storage) were in compliance with IRB regulations and APA Ethical Principles.

\section{Participants}

A total of 478 undergraduate students (66\% female) participated in this study. These students were a subgroup of a larger sample and were selected based on the following criteria: (1) they identified as either Latino/a or White, (2) they had not previously studied abroad, and (3) they were not international students. These respondents had an average age of 18.63 years $(S D=1.27)$ and represented a wide range of income levels. In terms of ethnicity and generational status, $60.7 \%$ were classified as CG (50 Latino/a and 244 White) and $39.3 \%$ as FG (116 Latino/a and 74 White). These students were $75.4 \%$ first year, $15.7 \%$ sophomores, $5.2 \%$ juniors and 3.3\% seniors from a small, residential liberal arts college in Southern California whose participation fulfilled an Introduction to Psychology course research requirement. Academic majors and intended majors included social sciences (36.9\%), mathematics and natural sciences (25.1\%), business (16.2 \%), humanities $(12.2 \%)$, and undecided or other (9.7\%). A total of $25 \%$ of participants reported speaking a 
language other than English at home and 77.3\% had traveled outside of the United States, the majority of whom as tourists (67.1\%).

\section{Instruments and Procedure}

Students who volunteered to participate in this study were sent a link to the anonymous, online survey via e-mail. This questionnaire assessed basic demographic information, study abroad exposure, adventurousness, language interest, intercultural communication apprehension, and ethnocentrism. Concern about major completion and family attitudes were assessed using single item measures administered as part of a larger (pilot) inventory of study abroad expectations. These items were rated on a 7-point Likert scale with higher scores indicating greater agreement and were worded, respectively, as "It would be difficult to complete my major if I were to participate in a study abroad program" and (reverse scored) "My family would be enthusiastic about my participation in a study abroad program.”

Demographic items. The demographic items included age, gender, ethnicity, year in college, academic major, heritage language, generational status, previous travel experience, family income, and number of hours in paid work weekly during the school year.

Study abroad self-perceptions. Three individual items assessed study abroad selfperceptions. These included a binary (yes/no) measure of intent ("Do you plan to study abroad in the future?"; lower scores indicate greater intent) and two Likert scale items, assessing perceived likelihood ("How likely or unlikely is it that you will study abroad during your years in college?; higher scores indicate greater likelihood) and ease of imagining ("How difficult or easy is it for you to imagine yourself studying abroad?"; higher scores indicate greater ease).

Study abroad exposure. A 3-item composite variable was developed by the authors to assess study abroad exposure $(\alpha=.79)$ consisting of ordinal items assessing the frequency with which respondents had discussed study abroad with faculty/staff, family, and peers. Higher scores indicate greater exposure.

Adventurousness. A 10-item subscale of the International Personality Item Pool Openness to Experience measure was used to assess Adventurousness (Goldberg, et al., 2006; $\alpha=.80$ ). Higher scores indicate greater adventurousness. Previous studies support the reliability, validity, and factor structure of this measure (Ehrhart et al., 2008; Johnson, 2014).

Language interest. The 6-item Hembroff and Rusz (1993) Interest in Foreign Languages Scale was used to assess attitudes about the value of language learning $(\alpha=.87)$. Higher scores indicate a greater value. The reliability and validity of this measure has been documented (Goldstein \& Kim, 2006; Hembroff \& Rusz, 1993).

Personal Report of Intercultural Communication Apprehension. Neuliep and McCroskey's (1997a) 14-item Personal Report of Intercultural Communication Apprehension $(\alpha=.95)$ assesses anxiety associated with real or anticipated intercultural interaction. Higher scores on this scale indicate greater apprehension. Previous research has demonstrated the internal consistency of this measure (Lin \& Rancer, 2003).

Generalized Ethnocentrism Scale. Neuliep and McCroskey's (1997b) Generalized Ethnocentrism Scale $(\alpha=.90)$ is a 22 -item measure that assesses individual differences in 
ethnocentrism. Higher scores indicate greater ethnocentrism. Several studies support the reliability and validity of this measure (Neuliep, 2002; Neuliep, \& McCroskey, 1997b).

\section{Data Analysis}

Data analyses took an intersectional approach to assess the impact of generational status and ethnicity on study abroad-related attitudes. The initial analyses investigated the interaction between generational status and ethnicity for each of the three study abroad self-perception items. Then, to investigate group differences in predictors of study abroad intent we used a two-stage process. First, we conducted separate logistic regression analyses for CG and FG students with the complete set of variables. Next, using only significant predictors, we conducted four separate, logistic regression analyses to identify predictors of study abroad intent for each (generational status by ethnicity) subgroup. Given the relatively small subsamples in our study and the number of possible interaction terms, we expected that the results of subgroup analyses would be more statistically sound and interpretable than were we to use a multiplicative approach examining interactions between significant predictors, generational status, and ethnicity (Christoffersen, 2017; Mcmaster \& Cook, 2018).

\section{Results}

Binary logistic regression was conducted to determine whether intent to study abroad could be predicted by generational status, ethnicity, or the generational status by ethnicity interaction term. A test of the full model against a constant only model was not statistically significant, indicating that the predictors could not reliably distinguish between students who did and did not intend to study abroad ( $\left.\chi^{2}=4.62, p=n s, d f=3\right)$. In fact, the majority of students across ethnic and generational groups indicated that they planned to study abroad, including $80 \%$ of White CG, $74 \%$ of Latino/a CG, $72 \%$ of White FG, and $74 \%$ of Latino/a FG students.

Table 1. Correlations for Ordinal Predictors and Study Abroad Self-Perception Items

\begin{tabular}{|c|c|c|c|c|c|}
\hline \multicolumn{2}{|c|}{ Variable } & Mean & SD & $\begin{array}{l}\text { Ease of } \\
\text { Imagining }\end{array}$ & $\begin{array}{l}\text { Perceived } \\
\text { Likelihood }\end{array}$ \\
\hline 1. & $\begin{array}{l}\text { Ease of } \\
\text { Imagining }\end{array}$ & 4.84 & 1.86 & --- & $.77 * \star$ \\
\hline 2. & $\begin{array}{l}\text { Perceived } \\
\text { Likelihood }\end{array}$ & 5.11 & 1.91 & $.77 * *$ & --- \\
\hline 3. & Income & 4.14 & 1.84 & $.23 * *$ & $.21 * \star$ \\
\hline 4. & $\begin{array}{l}\text { Major } \\
\text { Completion }\end{array}$ & 4.20 & 1.60 & $-.25 * *$ & $-.28 * *$ \\
\hline 5. & Family Attitudes & 5.62 & 1.44 & $.43 * *$ & $.48 * *$ \\
\hline 6. & Exposure & 2.94 & 0.97 & $.53 * *$ & $.60 * \star$ \\
\hline 7. & Adventurousness & 4.53 & 0.87 & $.30 * *$ & $.32 * \star$ \\
\hline & $\begin{array}{l}\text { Language } \\
\text { Interest }\end{array}$ & 5.82 & 0.90 & $.13^{*}$ & $.18 * *$ \\
\hline 9. & $\begin{array}{l}\text { Intercultural } \\
\text { Communication } \\
\text { Apprehension }\end{array}$ & 2.91 & 1.05 & $-.20 * *$ & $-.10 *$ \\
\hline & Ethnocentrism & 2.46 & 0.70 & -.09 & $-.10 *$ \\
\hline
\end{tabular}

Note: Items rated on a 7-point scale; ${ }^{*} p<.05 . * * p<.001$. 
Separate 2 (generational status) x 2 (ethnicity) ANOVAs were computed for the single-item measures of ease of imagining oneself studying abroad and perceived likelihood of studying abroad (see Table 1 ). For the ease of imagining item, there was a main effect for generational status, $F(1,468)=13.12, p<.001, \eta_{\mathrm{p}}{ }^{2}=.03$, with CG students $(M=5.23$, $S D=1.82)$ scoring significantly higher than FG students $(M=4.17, S D=1.77)$. There was also a main effect for ethnicity $F(1,468)=19.69, p<.001, \eta_{\mathrm{p}}{ }^{2}=.04$, with White students $(M$ $=5.22, S D=1.82)$ scoring significantly higher than Latino/a students $(M=4.04, S D=1.72)$. The interaction was not significant, $F(1,468)=0.03, p=$ ns. A similar pattern emerged for the perceived likelihood item, with a main effect for generational status, $F(1,405)=7.17, p$ $<.01, \eta_{\mathrm{p}}^{2}=.02$ with CG students $(M=5.46, S D=1.83)$ scoring significantly higher than FG students $(M=4.55, S D=1.92)$, and for ethnicity $F(1,405)=9.43, p<.005, \eta_{\mathrm{p}}{ }^{2}=.02$, with White students $(M=5.45, S D=1.86)$ scoring significantly higher than Latino/a students $(M=4.48$, $S D=1.86)$. The interaction was not significant, $F(1,405)=0.01, p=\mathrm{ns})$.

Table 2. Binary Logistic Regression Coefficients for Study Abroad Intent by Generational Status

Generational Status

\begin{tabular}{|c|c|c|c|c|}
\hline & \\
\hline & \multicolumn{2}{|c|}{ Continuing-generation } & \multicolumn{2}{|c|}{ First-generation } \\
\hline & Odds Ratio & 95\% C.I. & Odds Ratio & 95\% C.I. \\
\hline Gender & 1.03 & {$[0.44,2.41]$} & 0.97 & {$[0.37,2.60]$} \\
\hline Ethnicity & 0.87 & {$[0.30,2.49]$} & 1.32 & {$[0.48,3.64]$} \\
\hline Home Language & 1.39 & {$[0.40,4.82]$} & 0.88 & {$[0.32,2.44]$} \\
\hline Family Income & 1.02 & {$[0.82,1.28]$} & 1.14 & {$[0.85,1.54]$} \\
\hline Major Completion & 1.74 & {$[1.34,2.25]$} & 1.44 & {$[1.10,1.88]$} \\
\hline Family Attitudes & 0.78 & {$[0.59,1.05]$} & 0.85 & {$[0.63,1.16]$} \\
\hline Exposure & 0.40 & {$[0.25,0.63]$} & 0.17 & {$[0.09,0.34]$} \\
\hline Adventurousness & 0.44 & {$[0.27,0.73]$} & 0.71 & {$[0.40,1.24]$} \\
\hline Language Interest & 0.58 & {$[0.34,0.96]$} & 0.74 & {$[0.42,1.30]$} \\
\hline Intercultural & 0.60 & {$[0.40,0.90]$} & 0.81 & {$[0.52,1.26]$} \\
\hline \multicolumn{5}{|l|}{ Communication } \\
\hline \multicolumn{5}{|l|}{ Apprehension } \\
\hline Ethnocentrism & 0.83 & {$[0.44,1.55]$} & 0.88 & {$[0.42,1.81]$} \\
\hline$N$ & 234 & & 141 & \\
\hline
\end{tabular}

Notes: Hosmer and Lemeshow test shows $\mathrm{CG} \chi^{2}=3.61, p>.05, \mathrm{FG} \chi^{2}=9.46, p>.05$ for the multivariate model. Statistically significant $P$-values are indicated by bold font.

Separate binary logistic regression analyses were used to determine the combination of variables that best predict intent to study abroad for FG and CG students. Variables were entered simultaneously and included gender, ethnicity, heritage language, income, major completion concern, family attitudes, exposure, language interest, adventurousness, intercultural communication apprehension, and ethnocentrism. To reduce the number of variables, weekly hours worked was dropped from the analyses since it was significantly correlated with income $\left(\mathrm{r}^{2}=.42, p<.001\right)$. For both the FG and CG analyses, a test of the full model against a constant only model was statistically significant (FG $\chi^{2}=$ 70.73, $p<.001, d f=11 ; \mathrm{CG} \chi^{2}=102.47, p<.001, d f=11$ ). Major completion and exposure were the only significant individual predictors of study abroad intent for FG students. These students were less likely to intend to study abroad if they had had little exposure to study abroad $(B=-1.75, S E=.34, p<.001)$ or were concerned that study abroad would interfere with completing their major $(B=.36, S E=.14, p<.01)$ For CG students, study abroad intent was predicted by the exposure $(B=-.92, S E=.24, p<.001)$ and major completion $(B=.55, S E$ 
$=.13, p<.001)$ variables along with language interest $(B=-.55, S E=.26, p<.05)$, adventurousness $(B=-.82, S E=.26, p<.005)$, and intercultural communication apprehension $(B=-.51, S E=.21, p<.05)$. Like the FG students, the CG students were less likely to intend to study abroad if they had had little exposure to study abroad or were concerned that study abroad would interfere with completing their major. In addition, the CG students' intent to study abroad also decreased with lower levels of language interest and adventurousness. Contrary to our predictions, intent to study abroad was predicted by higher intercultural communication apprehension, a finding we address in the Discussion. The Nagelkerke's $\mathrm{R}^{2}$ indicated that the FG model explained $46.5 \%$ of the variation in intent; $81.5 \%$ of cases were correctly classified. The CG model explained $47.4 \%$ of the variation in intent; $85 \%$ of cases were correctly classified (see Table 2 for odds ratios).

Table 3. Binary Logistic Regression Coefficients for Study Abroad Intent by Generational Status and Ethnicity

\begin{tabular}{lllllllll} 
& \multicolumn{2}{c}{ White CG } & \multicolumn{2}{c}{ Latino/a CG } & \multicolumn{2}{c}{ White FG } & \multicolumn{2}{c}{ Latino/a FG } \\
\hline & $\begin{array}{l}\text { Odd } \\
\text { S }\end{array}$ & $95 \%$ C.I. & $\begin{array}{l}\text { Odds } \\
\text { Ratio }\end{array}$ & $95 \%$ C.I. & $\begin{array}{l}\text { Odds } \\
\text { Ratio }\end{array}$ & $95 \%$ C.I. & $\begin{array}{l}\text { Odds } \\
\text { Ratio }\end{array}$ & $95 \%$ C.I. \\
& Ratio & & & & & & & \\
\hline Major Completion & $\mathbf{1 . 9 1}$ & {$[1.43,2.57]$} & 1.29 & {$[0.76,2.18]$} & $\mathbf{1 . 6 0}$ & {$[1.03,2.47]$} & 1.32 & {$[0.93,1.88]$} \\
Exposure & $\mathbf{0 . 3 7}$ & {$[0.24,0.59]$} & $\mathbf{0 . 1 0}$ & {$[0.03,0.45]$} & $\mathbf{0 . 0 8}$ & {$[0.02,0.33]$} & $\mathbf{0 . 2 2}$ & {$[0.10,0.47]$} \\
Language Interest & $\mathbf{0 . 5 5}$ & {$[0.35,0.87]$} & 0.85 & {$[0.39,1.85]$} & 0.69 & {$[0.26,1.79]$} & 0.75 & {$[0.39,1.42]$} \\
Adventurousness & $\mathbf{0 . 4 3}$ & {$[0.25,0.75]$} & 0.32 & {$[0.09,1.10]$} & 0.42 & {$[0.16,1.14]$} & 0.96 & {$[0.47,1.96]$} \\
Intercultural & $\mathbf{0 . 5 2}$ & {$[0.33,0.83]$} & 1.76 & {$[0.53,5.78]$} & 0.93 & {$[0.43,2.04]$} & 0.78 & {$[0.48,1.25]$}
\end{tabular}

Communication

Apprehension

\begin{tabular}{lrrr}
$N$ & 240 & 50 & 72 \\
\hline
\end{tabular}

Notes: Hosmer and Lemeshow test shows White $\mathrm{CG} \chi^{2}=7.01, p>.05$, Latino/a CG $\chi^{2}=7.10, p>.05$, White FG $\chi^{2}=$ $9.86, p>.05$, Latino/a FG $\chi^{2}=7.72, p>.05$, for the multivariate model. Statistically significant $P$-values are indicated by bold font.

To assess the intersectionality of generational status and ethnicity, additional binary logistic regression analyses were conducted for the four subsamples using the significant individual predictors of intent (exposure, major completion, language interest, adventurousness, and intercultural communication apprehension). A test of the full model against a constant only model was significant for each subgroup (Latino/a $C G \chi^{2}=21.85 .63$, $p<.005, d f=5$; White CG $\chi^{2}=86.04, p<.001, d f=5$; Latino/a FG $\chi^{2}=32.24, p<.001, d f=5$; White $\mathrm{FG \chi}{ }^{2}=41.41, p<.001, d f=5$ ). The Nagelkerke's $\mathrm{R}^{2}$ indicated that the Latino/a CG model explained $51.9 \%$ of the variation in intent with $78 \%$ of cases correctly classified and the White CG model explained $47.7 \%$ of the variation in intent with $85.8 \%$ of cases correctly classified. The Latino/a FG model explained $36.3 \%$ of the variation in intent with $77.2 \%$ of cases correctly classified and the White FG model explained $64 \%$ of the variation in intent with $88.6 \%$ of cases correctly classified. Exposure was the only significant individual predictor of study abroad intent for Latino/a CG $(B=-2.22, S E=.73, p<.005)$ and Latino/a FG students $(B=-1.51, S E=.38, p<.001)$, and exposure $(B=-2.48, S E=.70, p<.001)$ and major completion $(B=.47, S E=.22, p<.05)$ predicted intent for White FG students, with students less likely to intend to study abroad if they had had little exposure to study abroad or were concerned that study abroad would interfere with completing their major. For White CG students, exposure $(B=-.98, S E=.24, p<.001)$ and major completion $(B=.65, S E$ $=.15, p<.001)$ were also significant predictors of intent, as were language interest $(B=-.59$, $S E=.23, p<.05)$, adventurousness $(B=-.84, S E=.28, p<.005)$, and intercultural 
communication apprehension ( $B=-.65, S E=.23, p<.01$ ). The White CG students' intent to study abroad also decreased with lower levels of language interest and adventurousness. Once again, contrary to our expectations, intent to study abroad was predicted by higher intercultural communication apprehension (see Table 3 for odds ratios).

To unpack the finding that exposure was a significant predictor of intent for each subgroup, we conducted exploratory two-way ANOVAs investigating the effect of generational status and ethnicity on overall exposure and exposure via discussions with faculty/staff. For overall exposure, there was a main effect for generational status, $F(1,477)$ $=4.81, p<.05, \eta_{\mathrm{p}}{ }^{2}=.01$, with CG students $(M=3.08, S D=0.98)$ scoring significantly higher than FG students $(M=2.71, S D=0.91)$. There was also a main effect for ethnicity $F(1,477)$ $=7.31, p<.01, \eta_{\mathrm{p}}^{2}=.02$, with White students $(M=3.07, S D=0.98)$ scoring significantly higher than Latino/a students $(M=2.68, S D=0.91)$. The interaction was not significant, $F(1$, $477)=1.45, p=\mathrm{ns}$ ). For discussions with faculty/staff there were no significant main effects, however the interaction was significant $\left[F(1,476)=4.43, p<.05, \eta_{\mathrm{p}}^{2}=.01\right]$ indicating that among the CG participants, White students $(M=2.33, S D=1.13)$ reported significantly more discussions about study abroad with faculty/staff than did Latino/a students $(M=1.90, S D=$ $0.84)$.

\section{Discussion}

The purpose of this study was to better understand the intersecting roles of ethnicity and generational status in intent to study abroad. We expected to find that CG students would score significantly higher than FG students and that White students would score significantly higher than Latino/a students on the study abroad self-perception items of intent, perceived likelihood, and ease of imagining. This was the case for two of these items. The study abroad intent item was not predicted by generational status, ethnicity, or their interaction. One possible explanation is that students perceive this item as indicating a desire to study abroad (Salisbury et al., 2009). If so, it is not surprising that many participants expressed this desire, particularly since they attend an institution where approximately $50 \%$ of students participate in study abroad programs. In contrast to intent, the perceived likelihood and ease of imagining items may tap into students' study abroadrelated self-concept. For both of these variables, CG students scored significantly higher than FG students and White students scored significantly higher than Latino/a students. It is well established that being able to envision oneself in an action is associated with the self-efficacy needed to perform that action (Bandura, 1977). Thus, additional research is needed to identify the source of study abroad self-perceptions and strategies for enhancing their inclusivity. For example, in line with the finding that vicarious experiences enhance self-efficacy (Bandura, 1977), hearing from FG study abroad returnees has been a successful strategy for increasing the study abroad participation of FG students (Tolan \& McCullers, 2018).

We expected that intercultural attitudes and adventurousness would be less relevant to FG and Latino/a students, who may have had considerable experience with negotiating unfamiliar environments and may be more focused on academic and career-related motives for study abroad. This was confirmed in the intersectional stage of our analyses. These findings qualify previous research indicating that personality and intercultural variables are predictive of study abroad intent. Rather, adventurousness, language interest and intercultural communication apprehension were only relevant to the study abroad intent of the White CG students. The finding that adventurousness was a predictor of intent 
for the White CG students and not for the other groups, adds credence to concerns raised about the adventure-oriented nature of promotional materials for study abroad programs and supports the suggestion that these images and narratives must deemphasize this component and instead prioritize positive educational outcomes that can prepare student sojourners for careers in a globally interconnected world (Gathogo \& Horton, 2018). In addition, the finding that language interest was predictive of study abroad intent for the White CG students but not for the other groups has important implications. As indicated in previous research, for White CG students, campus activities and pre-departure preparation aimed at developing and enhancing intercultural skills and attitudes appears to be central to interest in study abroad participation. For Latino/a students and White FG students, the ability to cross cultures may be an existing strength which advisors, study abroad recruiters, and pre-departure trainers can emphasize and build upon to enhance the self-efficacy required for study abroad participation.

We were puzzled by the finding that for CG students as a whole, and White CG students in particular, the regression results indicated greater intercultural communication apprehension was predictive of intent to study abroad. Although it is possible that this finding was a result of intercorrelations among variables, these associations did not approach standard criteria for multicollinearity (Berry \& Feldman, 1985). In addition, posthoc analysis of group means found no significant differences between the intercultural communication apprehension scores of those who did and did not intend to study abroad, and, with the exception of the Latino/a FG group, the means indicated lower apprehension associated with intent to study abroad (as would be expected). Future research might explore alternative strategies for assessing anxiety associated with intercultural interaction as well as the possibility that intercultural communication apprehension serves as a motivator for Latino/a FG students to seek experiences abroad.

Across groups, exposure was the strongest predictor of study abroad intent. In addition, White and CG students reported greater exposure to study abroad than did Latino/a and FG students, respectively. Furthermore, within the CG group, Latino/as reported significantly fewer discussions about study abroad with faculty/staff than did White students. We acknowledge the possibility that intent to study abroad may to some extent drive exposure, rather than the reverse, though we believe that it is highly unlikely that this is an entirely unidirectional process, particularly for students early in their college careers. Even if it were the case that ethnic differences in discussions with advisors are a result of differences in study abroad intent, these findings suggest that faculty and staff should be compensating for group differences in information seeking by broaching the topic of study abroad with students who do not initiate such discussions. Academic advisors can play an important role in diversifying study abroad participation by providing information about study abroad opportunities to those who do not fit the profile of the typical participant (e.g., White, affluent female) and by detailing the relevance of this HIP for academic goals and career opportunities. The ability of advisors to do so, however, may require that they receive training to enhance cultural competence (Torres et al., 2019). Other strategies for familiarizing students with study abroad include targeted presentations to organizations attended by underrepresented students during the first years of college, facilitating attendance at study abroad fairs, assisting with applications and financial aid, and involving family members in information sessions (Martinez et al., 2010). 


\section{Limitations and Future Research}

Our sample is limited in some important ways. The data come from a single, fouryear institution, which may not be representative in terms of its demographics or opportunities for study abroad. Furthermore, the size of our sample did not allow us to address intersectionality with other identities (e.g., sexual orientation, disability) or withingroup diversity among the Latino/a students (e.g., ethnic origin, heritage language use, level of acculturation). Finally, we focused on intended, rather than actual, enrollment in study abroad programs. Longitudinal research is needed to more accurately assess the factors that determine FG and Latino/a students' study abroad participation.

Several unanswered questions remain from the current study. It is not clear why income was not a predictor of study abroad, particularly among the FG students. One possibility is that these students attend an institution which maintains an on-campus fee structure for those who study abroad for a semester. In addition, there is some indication that gender may interact with income to predict study abroad intent (Hurst, 2019), a possibility that was not investigated in the current study. It is also unclear why major completion was a predictor for White students, regardless of generational status, and not for Latino/a students. Future research might assess, in greater depth, students' expectations about the academic consequences of study abroad. Finally, we did not investigate the degree to which study abroad intent might be influenced by concerns about experiencing prejudice or stereotyping abroad (e.g., Sweeney, 2013). Future research might explore the extent to which students from underrepresented groups anticipate discriminatory treatment from members of the host culture or from home country peers (Brux \& Fry, 2010; Willis, 2015).

\section{Conclusion}

This study identified exposure as a source of inequality central to study abroad intent. Latino/a and FG students were less likely than White and CG students respectively to be exposed to study abroad or to be able to envision themselves as participants. Furthermore, White CG students were more likely than Latino/a and FG students to have discussed study abroad with a faculty/staff member. Additional research is needed to investigate the nature, mechanism, and content of exposure to study abroad and how it varies with student demographics and identities. These findings support the value of an intersectional approach to understanding study abroad intent, participation, and outcomes. By investigating the role of study abroad-related life experiences and circumstances across interacting identities, we can better understand and address potential inequities in this important, high impact practice.

\section{References}

Azmitia, M., Sumabat-Estrada, G., Cheong, Y., \& Covarrubias, R. (2018). “Dropping out is not an option”: How educationally resilient first-generation students see the future. New Directions for Child and Adolescent Development, 160, 89-100. https://doi.org/10.1002/cad.20240

Bandura, A. (1997). Self-efficacy: The exercise of control. Freeman.

Berry, W. D., \& Feldman, S. (1985). Multiple regression in practice. Sage.

Blake, D., Gasman, M., Esmieu, P. '., Castro Samayoa, A., \& Cener, J. (2019). Culturally relevant study abroad for students of color: Lessons from the Frederick Douglass Global Fellowship in London. Journal of Diversity in Higher Education, 13(2), 158-168. https://doi.org/10.1037/dhe0000112 
Brux, J. M., \& Fry, B. (2010). Multicultural students in study abroad: Their interests, their issues, and their constraints. Journal of Studies in International Education, 14(5), 508-527. https://doi.org/10.1177/1028315309342486

Cataldi, E. F., Bennett, C. T., \& Chen, X. (2018). First-generation college students: College access, persistence, and postbachelor's outcomes. Stats in Brief. U.S. Department of Education. https://nces.ed.gov/pubsearch/pubsinfo.asp?pubid=2018421

Chang, A. (2017). "Call me a little critical if you will”: Counterstories of Latinas studying abroad in Guatemala. Journal of Hispanic Higher Education, 16(1), 3-23. https://doi.org/10.1177/1538192715614900

Christoffersen, A. (2017). Intersectional approaches to equality research and data. London, UK: Equality Challenge Unit. http://www.ecu.ac.uk/wpcontent/uploads/2017/04/Research and data briefing_2 Intersectional approaches to equality rese arch and data.pdf

De Onis, C. (2017). What's in an ' $x$ "?: An exchange about the politics of "Latinx." Chiricú Journal: Latina/o Literatures, Arts, and Cultures. 1(2), 78-91. https://doi.org/10.2979/chiricu.1.2.07

Demetriou, C., Meece, J., Eaker-Rich, D., \& Powell, C. (2017). The activities, roles, and relationships of successful first-generation college students. Journal of College Student Development, 58(1), 19-36. https://doi.org/10.1353/csd.2017.0001

Earnest, D. R., Rosenbusch, K. , Wallace-Williams, D., \& Keim, A. C. (2016). Study abroad in psychology: Increasing cultural competence through experiential learning. Teaching of Psychology, 43(1), 75-79. https://doi.org/10.1177/0098628315620889

Ehrhart, K. H., Roesch, S. C., Ehrhart, M. G., \& Kilian, B. (2008). A test of the factor structure equivalence of the 50-Item IPIP Five-Factor Model measure across gender and ethnic groups. Journal of Personality Assessment, 90(5), 507-516. https://doi.org/10.1080/00223890802248869

Engle, L. (2017). Underrepresented students in US study abroad: Investigating impacts. Institute of International Education. http://mobilitytoolkit.ie/wp-content/uploads/2017/12/UnderrepresentedStudents-and-Study-Abroad.pdf

Gathogo M., \& Horton Jr. D., (2018). The exclusionist framing of study abroad electronic advertising and its potential influence on students of colors participation. Journal for the Study of Postsecondary and Tertiary Education. 3, 59-76. https://doi.org/10.28945/4096

Goldberg, L. R., Johnson, J. A., Eber, H. W., Hogan, R., Ashton, M. C., Cloninger, C. R., \& Gough, H. C. (2006). The International Personality Item Pool and the future of public-domain personality measures. Journal of Research in Personality, 40 (1), 84-96. https://doi.org/10.1016/j.jrp.2005.08.007

Goldstein, S. B. (2015). Predictors of preference for the exported campus model of study abroad. Frontiers: The Interdisciplinary Journal of Study Abroad, 26 (1), 1-16. https://doi.org/10.36366/frontiers.v26i1.351

Goldstein, S. B., \& Kim, R. I. (2006). Predictors of U. S. college students' participation in study abroad programs: A longitudinal study. International Journal of Intercultural Relations, 30 (4), 507-521. http://dx.doi.org/10.1016/j.ijintrel.2005.10.001

Hembroff, L. A., \& Rusz, D. L. (1993). Minorities and overseas studies programs: Correlates of differential participation. Occasional Papers on International Educational Exchange: Research Series 30. Council on International Educational Exchange.

Hurst, A. L. (2019). Class and gender and predictors of study abroad participation among US liberal arts college students. Studies in Higher Education, 44(7), 1241-1255.

https://doi.org/10.1080/03075079.2018.1428948

Institute of International Education. (2020). Open Doors Report on International Educational Exchange. https://www.iie.org/Research-and-Insights/Open-Doors

Johnson, J. A. (2014). Measuring thirty facets of the Five Factor Model with a 120-item public domain inventory: Development of the IPIP-NEO-120. Journal of Research in Personality, 51, 78-89. https://doi.org/10.1016/j.jp. 2014.05.003

Kitsantas, A. (2004). Studying abroad: The role of college student's goals on the development of crosscultural skills and global understanding. College Student Journal, 38 (3), 441-452.

Kuh, G. D. (2008). High-impact educational practices: What they are, who has access to them, and why they matter. Association of American Colleges and Universities. 
Li, M., Olson, J. E., \& Frieze, I. H. (2013). Students' study abroad plans: The influence of motivational and personality factors. Frontiers: The Interdisciplinary Journal of Study Abroad, 23 (1), 73-89. https://doi.org/10.36366/frontiers.v23i1.330

Lin, Y., \& Rancer, A. S. (2003). Ethnocentrism, intercultural communication apprehension, intercultural willingness-to-communicate, and intentions to participate in and intercultural dialogue program: Testing a proposed model. Communication Research Reports, 20(1), 62-72. https://doi.org/10.1080/08824090309388800

Lu, C., Reddick, R., Dean, D., \& Pecero, V. (2015). Coloring up study abroad: Exploring Black students' decision to study in China. Journal of Student Affairs Research and Practice, 52(4), 440-451. https://doi.org/10.1080/19496591.2015.1050032

Luo, J., \& Jamieson-Drake, D. (2015). Predictors of study abroad intent, participation, and college outcomes. Research in Higher Education, 56(1), 29-56. https://doi.org/10.1007/s11162-014-9338-7

Martin, G. L. (2015). "Tightly Wound Rubber Bands": Exploring the college experiences of low-income, first-generation White students. Journal of Student Affairs Research and Practice, 52(3), 275-286. https://doi.org/10.1080/19496591.2015.1035384

Martinez, M. D., Ranjeet, B., \& Marx, H. A. (2010). Creating study abroad opportunities for first-generation college students. In R. Lewin (Ed.), The handbook of practice and research in study abroad: Higher education and the quest for global citizenship (pp. 527-542). Routledge.

McClure, K. R., Szelenyi, K., Niehaus, E., Anderson, A. A., \& Reed, J. (2010). “We just don’t have the possibility yet”: U.S. Latino/a narratives on study abroad. Journal of Student Affairs Research and Practice, 47(3), 363-382. https://doi.org/10.2202/1949-6605.6056

Mcmaster, N, C., \& Cook, R. (2018). The contribution of intersectionality to quantitative research into educational inequalities. Review of Education, 7(2), 271-292. https://doi.org/10.1002/rev3.3116

Museus, S. D., \& Griffin, K. A. (2011). Mapping the margins in higher education: On the promise of intersectionality frameworks in research and discourse. New Directions for Institutional Research, 2011(151), 5-13. https://doi.org/10.1002/ir.395

National Survey of Student Engagement (2020). Engagement insights: Survey findings on the quality of undergraduate education. Author. https://nsse.indiana.edu/

Neuliep, J. W. (2002). Assessing the reliability and validity of the Generalized Ethnocentrism Scale. Journal of Intercultural Communication Research, 31, 201-215.

Neuliep, J. W., \& McCroskey, J. C. (1997a). The development of intercultural and interethnic communication apprehension scales. Communication Research Reports, 14, 145-156.

Neuliep, J. W., \& McCroskey, J. C. (1997b). The development of a U.S. and generalized ethnocentrism scale. Communication Research Reports, 14, 385-398.

Opper, S., Teichler, U., \& Carlson, J. (1990). Impacts of study abroad programs on students and graduates. Jessica Kingsley Publishers.

Orbe, M. P. (2004). Negotiating multiple identities within multiple fames: An analysis of first-generation college students. Communication Education, 53(2), 131-149.

https://doi.org/10.1080/03634520410001682401

Pascarella, E. T., Pierson, C. T., Wolniak, G. C., \& Terenzini, P. T. (2004). First-generation college students: Additional evidence on college experiences and outcomes. The Journal of Higher Education, 75(3), 249-284. https://studentsuccess.unc.edu/wp-content/uploads/sites/10139/2016/02/75.3pascarella-1.pdf

Salinas, C. (2020). The Complexity of the " $x$ " in Latinx: How Latinx/a/o students relate to, identify with, and understand the term Latinx. Journal of Hispanic Higher Education. 19(2), 149-168. https://doi.org/10.1177/1538192719900382

Salisbury, M. H., Paulsen, M. B., \& Pascarella, E. T. (2011). Why do all the study abroad students look alike? Applying an integrated student choice model to explore differences in the factors that influence white and minority students' intent to study abroad. Research in Higher Education, 52, 123-150. https://doi.org/10.1007/s11162-010-9191-2

Salisbury, M.H., Umbach, P.D., Paulsen, M.B., \& Pascarella, E.T. (2009). Going global: Understanding the choice process of the intent to study abroad. Research in Higher Education, 50, 119-143. https://doi.org/10.1007/s11162-008-9111-x

Schroth, M. L., \& McCormack, W. A. (2000). Sensation seeking and need for achievement among studyabroad students. The Journal of Social Psychology, 140(4), 533-535. https://doi.org/10.1007/s11162008-9111-X 
Stephens, N. M., Fryberg, S. A., Markus, H. R., Johnson, C. S., \& Covarrubias, R. (2012). Unseen disadvantage: How American universities' focus on independence undermines the academic performance of first-generation college students. Journal of Personality and Social Psychology, 102(6), 1178-1197. https://doi.org/10.1037/a0027143

Stroud, A. H. (2010). Who plans (not) to study abroad? An examination of U.S. student intent. Journal of Studies in International Education, 14(5), 491-507. https://doi.org/10.1177/1028315309357942

Sweeney, K. (2013). Inclusive excellence and underrepresentation of students of color in study abroad. Frontiers: The Interdisciplinary Journal of Study Abroad, 23 (1), 1-21.

https://doi.org/10.36366/frontiers.v23i1.326

Tarrant, M. A., Rubin, D. L., \& Stoner, L. (2014). The added value of study abroad: Fostering a global citizenry. Journal of Studies in International Education, 18(2), 141-161.

https://doi.org/10.1177/1028315313497589

Tello, A. M., \& Lonn, M. R. (2017). The role of high school and college counselors in supporting the psychosocial and emotional needs of Latinx first-generation college students. The Professional Counselor, 7, 349-359. https://tpcjournal.nbcc.org/category/pdf-articles/volumes/volume-7/volume-7issue-4l

Tolan, M., \& McCullers, M. (2018). First-generation college students and study abroad: Examining the participation gap and successful strategies for promoting access. In H. B. Hamir \& N. Gozik (Eds.), Promoting inclusion in education abroad: A handbook of research and practice (pp. 61-81). Stylus.

Torres, V., Hernández, E., \& Martinez, S. (2019). Understanding the Latinx experience: Developmental and contextual influences. Stylus.

Toutkoushian, R. K., Stollberg, R. A., \& Slaton, K. A. (2018). Talking 'bout my generation: Defining "firstgeneration college students" in higher education research. Teachers College Record, 120(4), 1-38.

https://www.tcrecord.org/Content.asp?ContentId=22042U.S. Department of Education, National Center for Education Statistics. (2019). Status and Trends in the Education of Racial and Ethnic Groups 2018 (NCES 2019-038). Author. https://nces.ed.gov/pubs2019/2019038.pdf

Volpone, S. D., Marquardt, D. J., Casper, W. J., \& Avery, D. R. (2018). Minimizing cross-cultural maladaptation: How minority status facilitates change in international acculturation. Journal of Applied Psychology, 103(3), 249-269. http://dx.doi.org/10.1037/apl0000273

Whatley, M. (2017). Financing study abroad: An exploration of the influence of financial factors on student study abroad patterns. Journal of Studies in International Education, 21(5), 431-449. https://doi.org/10.1177/1028315317697798

Whatley, M. (2018). Toward an understanding of peer influence on undergraduate study abroad participation. Frontiers: The Interdisciplinary Journal of Study Abroad, 30(3), 51-71. https://doi.org/10.36366/frontiers.v30i3.421

Wick, D., Willis, T. Y., Rivera, J., Lueker, E., \& Hernandez, M. (2019). Assets-based learning abroad: First generation Latinx college students leveraging and increasing community cultural wealth in Costa Rica. Frontiers: The Interdisciplinary Journal of Study Abroad, 31(2), 63-85.

https://doi.org/10.36366/frontiers.v30i3.421

Wilkie, D. (2017, March/April). Supporting education abroad for underrepresented students. International Education, 52-55. https://www.nafsa.org/ie-magazine/2017/3/1/supporting-educationabroad-underrepresented-students

Willis, T. Y. (2015). “And still we rise”: Microaggressions and intersectionality in the study abroad experiences of Black women. Frontiers: The Interdisciplinary Journal of Study Abroad, 26 (1), 209230. https://doi.org/10.36366/frontiers.v26i1.367

Wynveen, C. J., Kyle, G. T., \& Tarrant, M. A. (2012). Study abroad experiences and global citizenship: Fostering proenvironmental behavior. Journal of Studies in International Education, 16(4), 334-352. https://doi.org/10.1177/1028315311426782

\section{Author Biographies}

Susan B. Goldstein is Professor of Psychology at the University of Redlands, where she teaches cross-cultural psychology and study abroad pre-departure and re-entry classes. She earned her B.A. from Oberlin College and her PhD from the University of Hawaii, Manoa, as an East-West Center grantee. Her research has focused on study abroad, intercultural 
attitudes, social justice allies, stigma, and strategies for diversifying the psychology curriculum.

Henry N. Lopez is an incoming PhD student at Iowa State University, where he will investigate culture of honor and culture and close relationships. Henry received his B.A. in Psychology and Spanish from the University of Redlands and his M.A. from San Diego State University. His research has focused on taking a cultural psychological approach to investigating implicit biases, and on barriers to study abroad for underrepresented students. 